\title{
How Do Committees Invent? and Ironies of Automation
}

ADRIAN COLYER

\section{THE FORMULATION OF CONWAY'S LAW AND THE COUNTERINTUITIVE CONSEQUENGES OF INCREASING LEVELS OF AUTOMATION}

De Lindy effect tells us that if a paper has been highly relevant for a long time, it's likely to continue being so for a long time to come as well. For this issue's selections I am going back to a couple of papers that have most definitely stood the test of time. The lessons they contain could continue to bear fruit for many more years.

My first choice, from 1968, is entitled "How Do Committees Invent?" This is the paper that gave us Conway's law, and while we all know that law today, author Melvin E. Conway provides a lot of great material that led up to the formulation of the law that bears his name. It's one of those wonderful papers that tends to give you fresh takeaways every time you come to it. It should be good for another 52 years, according to the Lindy effect; ;.

For my second choice we go forward in time to 1983 , with Lisanne Bainbridge's "Ironies of Automation." It's a classic treatise on the counterintuitive consequences of increasing levels of automation, and something ohso-relevant to this forthcoming decade. Where will the experts be when we need them?

For the complete column, go to https:Iqueue.acm.orgl TheMorningPaper $|7|$. 
Adrian Colyer is a venture partner with Accel in London, where his job is to help find and build great technology companies across Europe and Israel. Ilf you're working on an interesting technology-related business, he would love to hear from you: acolyer@accel.com.] Prior to joining Accel, he spent more than 20 years in technical roles, including CTO at Pivotal, VMware, and SpringSource.

Copyright 2020 held by ownerlauthor. Publication rights licensed to ACM. Reprinted with permission from https:/lblog.acolyer.org 